\title{
The Future and Potential of Non-Steady Flow Devices in Advanced Propulsion Designs
}

\author{
Michael Most, Charley Rodriguez, and Larry Head \\ Southern Illinois University Carbondale
}

\begin{abstract}
Conventional aircraft powerplants generate a propulsive force through the application of a relatively constant fluidic flow. In non-steady flow propulsion, an unevenness of fluidic pressure is developed and purposefully controlled with the objective of producing thrust. This paper reviews basic non-steady flow concepts and presents potential applications for emerging technologies.
\end{abstract}

\section{INTRODUCTION}

Some unsteadiness is characteristic of any propulsive flow. However, in nonsteady flow propulsion, an unevenness of fluidic pressure is developed and purposefully controlled with the objective of producing thrust. A non-steady flow device may be component or power plant. Examples include internal- and externalcombustion wave engines, valved and valveless pulse jets and wave rotors.

In comparison to steady flow devices, such as turbojets and propellers, those operating on the principle of nonsteady flow potentially offer several advantages. According to Foa (1960):

...the lowest entropy rise in combustion, for any given heat input and initial temperature, is obtained with non-steady modes, and that these modes also make possible the alternate exposure of moving parts to hot and cold gases, thereby permitting the use of higher peak temperatures. Thus, as far as the effect of combustion alone is concerned, non-steady modes appear capable of producing a higher cycle efficiency and a higher air specific impulse than could be produced by the best steady modes. [Further,] ..... non-steady thrust augmenters, which are wave exchangers, are believed to be potentially more efficient than any steady-flow thrust augmenter with the exception of the propeller. (p. 345)

The idea of using non-steady flows in the production of thrust is not new. Conceptualization of non-steady flow power plant designs date to approximately the beginning of the twentieth century, and proposals for gas turbines and jet engines based on non-steady combustion apparently preceded the straight-through, steady flow design of currently-produced turbomachines (Foa, 1960). By 1910, G. Marconnet had devised and patented a propulsion device that many consider the archetypical pulse jet (French patent number 412,478). Nonsteady flow devices are of many designs, some more practically applicable than others. Despite certain inherent advantages 
(discussed below) and the fact that nonsteady flow power plants were first proposed approximately a century ago, most of these designs remain, as yet, more theoretical than practical.

Reasons for lag in the development and application of non-steady flow devices are manifold, but the preeminent cause is that technology has not yet evolved to reduce certain losses inherent in non-steady flows. For example, Foa (1960) states that, with one exception (when the exhaust velocity is a square-wave function of time), "...supersonic diffuser losses are generally higher in pulsating than in steady flow...", and he also cites losses attributed to inefficiencies in non-steady exhaust flows (p. 345). Much remains to be improved, resolved or even fully understood. Areas requiring further research include wave propagation, shock, heat and viscous losses within wave rotor passages, mixing of nonuniform flow fields, leakage between wave rotor ports and passages, and mixing at gas/gas interfaces (Welch, Jones, \& Paxson, 1997).

\section{PULSE JETS}

The pulse jet generates a series of pressure pulses (or waves) to produce a directed propulsive jet. Several variations of the pulse combustor are possible. Timnat (1996) identified four, categorized according to the method employed to control the combustion processes and resulting pressure pulses: (a) mechanically valved, (b) rotary valved, (c) aerodynamically valved, also referred to as a valveless design, and (d) a valveless flow rectifier system.

Although the pulse jet was patented in 1910 and a number of desirable attributes are characteristic of this engine (e.g., simplicity of construction and operation, improved combustion intensity, reduced
$\mathrm{NO}_{\mathrm{x}}$ emissions, less smoke, and the potential for high cycle efficiencies), the pulse jet has generally not proven a viable means of propulsion-the notable exception being the pulse-jet-powered V-1 "buzz bomb" designed by the Germans for use during the Second World War. The high noise level associated with pulsed combustion remains problematic. This notwithstanding, Georgia Tech engineers have been working to develop pulse-jetpowered micro air vehicles, weighing only four ounces and having a wingspan of about six inches. Potential missions for such an aircraft include search and rescue operations, reconnaissance and near-earth remote sensing. "The favored concept for propulsion [of the micro air vehicle] is a pulse jet...which has no moving parts, and could also provide air for lift and flight control" (Nordwall, 1997, p. 70). The advantages associated with pulsed combustion remain attractive and efforts to refine and develop this non-steady flow device continue.

\section{WAVE ROTORS}

The Concept of Pressure Exchange

Non-steady flow propulsive devises frequently rely on the principle of "pressure exchange." "'Pressure exchange' is sometimes defined as the compression of a fluid from a pressure $P_{A}$ to a pressure $P_{B}$ at the expense of the expansion of another fluid from the pressure $P_{B}$ to the pressure $P$ A" (Foa, 1960, p. 223). Put in a more simplistic way: Pressure exchange may be defined as the process by which one expanding fluid applies a compressive force to another; in this process, compressing fluid pressure rises in proportion to the diminishment of pressure in that which expands.

\section{General Description}


Gas turbines operate on the principle of the Brayton cycle, an idealized thermodynamic model used to describe power development in a gas turbine engine. The Brayton cycle consists of the following events: (a) compression of the working fluid (gas), (b) addition of heat while maintaining gas constant pressure, (c) expansion of the gas in the turbine, and (d) heat rejection as exhaust. The higher the constant pressure at which heat is added, the more efficient the engine operates, producing higher specific power (SP) and lower specific fuel consumption (SFC) ${ }^{\mathrm{ii}}$. Thus, there is a drive in the gas turbine industry toward higher pressure ratio engines. However desirable, an increase in an engine's pressure ratio produces two undesirable side-effects that set constraints on power plant performance and design.

With the increase in compression necessary to boost pressures in the gas turbine comes an increase in operating temperatures. These temperatures, however, can be no higher than today's metallurgy and material technology will allow-if the temperature is too high, things begin to melt. From the days of the Whittle and von Ohain

ii These ratios measure the efficiency of airbreathing power plants and are useful in comparing the efficiency of one engine to that of another. Specific Power (SP) is defined here as the net shaft power or thrust the engine produces as compared to the mass flow of air taken into the power plant. SFC is the ratio of pounds of fuel burned per hour for each pound of thrust produced by the engine. A decrease in the rate of fuel consumption for a given power output, reduces (improves) the Specific Fuel Consumption (SFC) ratio. In other words, the lower the SFC ratio, the lower the fuel flow rate for a given power output and the more fuel efficient the engine. turbines, researches have focused on improving component cooling and developing materials (alloys, ceramics, composites) tolerant of elevated temperatures with the objective of producing higher pressure ratios in gas turbines for better performance. More recently evolved strategies include the use of thermal barrier coating.

A second side-effect of higher pressure ratios is that, as pressures go up, component sizes go down. Now, initially smaller component size may seem like a desirable attribute, producing smaller, lighter power plants, but consider the following. Small components are far more susceptible to performance degradation due to very close operating tolerances. A $10 \mathrm{mil}$ spacing between rotor and casing is likely not excessive for a big blade at the front of the compressor, but that same clearance for a small blade at the rear will have a huge impact on performance. To achieve very close tolerance during manufacture and maintain these during operation increases costs. To sustain small clearances over an engine's service life is difficult, and likely increases engine complexity, requiring refinements in some systems, such as electronic engine control, and the addition of others, such as active clearance control. Consequently, the development of more efficient turbomachinery has lagged as the result not only of the inability to increase combustion temperatures beyond a certain thermal limit, but also due to a threshold on the design size of components. The wave rotor may provide the means of overcoming these limitations.

Wave rotors are devices that use unsteady waves to exchange fluidic energy through the compression and expansion of air in a single, internal flow machine. The wave rotor consists of a bank of elongated tubes or passages assembled on a rotating 
cylinder. In current designs for turbomachinery topping cycle applications, these tubular passages are generally trapezoidal in cross section. As the cylinder, or drum, rotates inside its housing, each tubular passage periodically aligns with an inlet port to fill with air. The force of an unsteady pressure wave compresses the air, which exhausts from the tube as the opposite end aligns with an outlet port. In one rotational cycle of the drum, these waves propagate from one end of the tube to the other. Wave rotor designs may conceivably take any one of several multi-port configurations, with through-flow and reverse-flow variations further diversifying power plant options. "Two-port, four-port and nine-port wave rotors have been evaluated for gas turbine engine topping applications" (Welch, Jones, \& Paxson, 1997, p. 469).

\section{The Wave Rotor in Topping and Bottoming Cycles}

Turbine engine topping is the process through which it is possible to add heat to combustor gasses, elevating that fluid's temperature and pressure in comparison to those otherwise experienced, without significantly increasing the temperature of turbomachinery components. The term, "topping" is descriptive of the point in the Brayton Thermodynamic Cycle where the wave rotor functions to improve turbomachinery performance-that is, at the top, in the high pressure area between the last stage of compression and the combustor. Consider the following quote, attributable to Daniel E. Paxson, NASA engineer whose contributions to propulsion include substantial wave rotor research:

A typical aircraft gas turbine performs this cycle [the Brayton Cycle] using several shafts. The fan say, and first few compressor stages (the compression and expansion process are accomplished over multiple stages) are physically connected to a low pressure turbine (e.g. expander) in the rear of the machine. On another shaft, spinning completely independently, are the latter (high) stages of the compressor and the first (high pressure) stages of the turbine. Generally, the inner spool or shaft spins much faster than the outer spool. This has to do with aerodynamic properties of the airfoils making up the compressor and turbine stages. If it spins faster, it is more efficient. The inner shaft is, of course, thermodynamically balanced. That is, the shaft work generated by the turbine exactly balances that required by the high- pressure compressor. Sitting on top of all of this is the combustor, which adds heat to the compressed flow and delivers it to the turbine. The whole purpose of this inner shaft is to raise the pressure of the working fluid before heat is added. The shaft power from the low-pressure turbine drives the fan and the lower compression stages and whatever energy is left over can be expanded through a nozzle to get jet thrust.

This inner shaft system of compressor and turbine is essentially a topping cycle...[The wave rotor] acts like a third shaft, compressing and expanding in a balanced manner. The difference is that it achieves the cycle using gasdynamic waves instead of airfoils... (personal communication with Michael Most, April 22, 1998)

Despite considerable recent researches on the application of the wave rotor in topping cycles (NASA, General Electric and Rolls-Royce have all tested wave rotors for use in turboshaft and turbofan power plants), use of this technology in a bottoming cycle is not new. The term "bottoming cycle" refers to 
placement of the wave rotor at the bottom, or low pressure portion of the thermodynamic cycle. Since they initially compress the working fluid, any supercharger/turbocharger operates as a bottoming cycle machine. In a turbocharger, the compressor is driven by a turbine which expands the exhaust gases. Just as in the topping cycle, the shaft work provided by the turbine is exactly that required by the compressor. Since a wave rotor is just a matched gasdynamic compressor and turbine, it can perform equally well as either a topping or bottoming cycle device. When used in the bottoming cycle, the spinning of a wave rotor by connecting it to a car engine (say, driven through a belt/pulley system) is only for valving purposes, and therefore consumes very little power. As a turbocharger, the wave rotor provides no thermodynamic advantages over conventional turbochargers. It does, however, offer very fast response time (i.e., does not suffer the droop or lag that a turbocharger experiences as it bootstraps itself), relative simplicity in terms of manufacture and some potential pollution reduction due to an inherent egr feature of the wave cycle.

The idea of using wave rotors as an integral component in power plant design dates to the early 1940's. Wave rotor bottoming cycle compressors for locomotive diesel engines have been available since 1947. In the 1950's wave rotors were touted as a viable alternative to conventional turbochargers in the improvement of aircraft piston engine performance (Taussig, 1984 ). More recently in Europe, Mazda sold automobile engines with wave rotor turbochargers. Today, research into the application of wave rotor bottoming cycle technology continues as "Caterpillar Inc. is currently investigating wave rotor turbochargers for diesel-powered machinery..." (Paxson, personal communication with Michael Most April 22, 1998).

\section{Four-Port, Through-Flow Wave Rotor Topping}

Among conceivable configurations are two-, three-, four-, eight- and nine-port wave rotors. Another design option is to direct the working fluid through the rotor in either a reverse-flow or through-flow passage/port design. Although offering the potential advantage of increased capacity in comparison to the through-flow wave rotor, the reverse flow design has serious limitations. If the four-port, reverse-flow wave rotor has a single cycle per revolution, one end of the rotor (compressor inlet) remains relatively cool while the other (turbine outlet) becomes heated. Further, a buffer layer of air remains in the passages unless each reverse-flow cycle is followed by an opposite-flow, "mirror-image" cycle. "In this approach, a passage would experience two four-port, reverse-flow cycles, one the mirror image of the other, as it rotates past eight ports in one rotor revolution" (Welch, Jones, \& Paxson, 1997, p. 470). The four-port, reverse-flow rotor is therefore complex, requiring twice the housing ports and associated ducting.

Of all possible wave rotor configurations, the four-port, through-flow design is the preeminently logical choice for immediate development, since it most readily adapts to topping current-technology turbomachines. Using a through-flow, fourport wave rotor to produce a topping cycle, air from the turbine's compressor is ported into the wave rotor through one of two input ports. (The other input port directs air from the combustor to the rotor.) The air flows into the rotor passages to be compressed by a series of compression or shock waves. This compressed air exits the housing through one of two outlet ports to flow to 
the turbine's combustion chamber. (The other outlet port leads to the engine's turbine section.) Heated from combustion in the burner, the air is returned to the wave rotor and directed into the tubular passages through the second inlet duct. This heated airflow returning to the wave rotor introduces a shock wave which propagates axially to further compress the air traversing the passage en route from the compressor to the combustor. As the drum continues to rotate, the inlet from the combustor closes, trapping the air in the passage at a very high pressure. With further rotation, the passage opens into the port leading to the engine's turbine section. Since, while traversing the tubular passages, air first compresses, then expands, the wave rotor combines, in a single machine, the functions of both compressor and turbine.

Use of the wave rotor for turbine engine topping is particularly attractive because this nonsteady flow device possesses an inherent self-cooling feature (Welch, Jones, \& Paxson, 1997):

In general, the wave rotor passages are alternately exposed to cold and hot gases at [high] frequencies...and, therefore, the rotor assumes a constant temperature, which is significantly lower than the peak gas temperature in the rotor. This selfcooling feature enables topping in turbine-inlet-temperature-limited engines; that is, the wave rotor topping increases the pressure and temperature at which heat is added in the burner without increasing the temperature of the turbomachinery components. (p. 469)

According to NASA researchers at Lewis Research Center, when incorporated into a small power plant $(5 \mathrm{lbm} / \mathrm{s})$ the mean wave rotor passage wall temperature is approximately $360^{\circ}$ Centigrade below combustor discharge pressure. Because wave rotor designs inherently operate cooler, increased pressure ratios and combustion temperatures result, with a corresponding potential for significantly improved power plant performance (Wilson \& Paxson, 1995):

...By using a wave rotor topping cycle, combustion temperatures greater than the turbine inlet temperature can be used, since the gas leaving the combustor is cooled in the expansion before being sent to the turbine. Also, since the rotor is washed alternately by cool inlet air and hot combustion gas, it is selfcooled, and attains a steady state temperature significantly lower than the combustion temperature. By increasing the overall cycle pressure ratio, and allowing higher combustion temperatures, the wave rotor topping cycle offers a potential route to higher engine efficiency. ( $p$. 1)

By using a wave rotor in turbomachinery topping cycles, the pressure and temperature at which heat is added in the combustor increases without elevating the temperature of engine components. This results in higher pressure ratios, and consequently, increased specific performance and decreased specific fuel consumption without substantially increasing turbomachinery temperatures. 


\section{Technological Promise of Wave Rotor Design}

Many advantages accrue in the use of the wave rotor to produce a topping cycle for gas turbine engines, including high efficiencies, quick response and installation flexibility. Consider the following. excerpted from Taussig (1984):

....the compression - and - exhaust process is accomplished by gasdynamic waves and not by the motion of any solid pistons or by the rotor wheel, so that no change in solid-body inertia is required for it to respond quickly to load changes. Since there is no analog to turbine blade tip leakage in the wave rotor, the component efficiency of this device is comparatively high for small engines. For the same reason, the wave rotor need not have a small shaft diameter. Therefore, it can be mounted either coaxially with the lower pressure spools, or at right angles as in the eccentric configuration. (p. 61)

In comparison to conventional turbomachinery, wave rotor component stresses are reduced due to a much lower spin rate, and the blade stresses imposed on conventional axial-flow compressors do not exist. Wave rotors have the potential to dramatically improve performance in terms of specific power and specific fuel consumption without significantly increasing power plant size.

When used in a topping cycle, wave rotor designs inherently operate cooler, allowing increased power plant pressure ratios and combustion temperatures for improved performance. Increased pressure ratios reduce $\mathrm{NO}_{\mathrm{x}}$ (oxides of nitrogen) emissions, improve specific power and decrease thrust specific fuel consumption. Research at NASA's Lewis Research Center in Cleveland, Ohio suggests that, in comparison to large turbofan power plants, small (400 to $600 \mathrm{shp}$ ) and intermediate (3000 to $4000 \mathrm{shp}$ ) turboshaft engines will benefit the most from wave rotor technology (Welch, Jones, \& Paxson, 1995):

...the specific power enhancement of the small and intermediate turboshaft engines is $+21 \%$ (i.e., increased by $21 \%$ of baseline SP [specific power] and $+19 \%$, respectively, and the SFC levels are reduced (enhanced) by $17 \%$ and $16 \%$ respectively...The large turbofan $[80,000$ to 100,000 lbs. of thrust] wave rotor performance is severely penalized by $21 \%$ (core flow) cooling bleed. The penalized wave rotor pressure ratio...leads to SFC reduction of 3\% and SP enhancement of 3\%. These modest improvements might suggest discounting wave rotor-topping in the large high bypass turbofans... (p.

5)

\section{CONCLUSION}

In writing this article, the authors have not intended to produce an empirical study. Rather, it was our goal to give the reader perspective on a topic of significance to aviation and insight into a technology that is both emerging and unfamiliar to many. We elected to achieve this goal through an historical, informational account of nonsteady flow propulsion and a look at the promise of future powerplant applications. As technology continues to evolve, realizing the potential of wave rotors for topping gas turbines becomes more likely. At some point, it may even be possible to construct a radically different engine where, in a single 
power plant, the internal combustion wave rotor performs the functions of compressor, combustor and turbine---a wave engine. 


\section{REFERENCES}

Foa, J. V. (1960). Elements of Flight Propulsion. (First ed.). New York: John Wiley \& Sons, Inc.

Nordwall, B. D. (1997, April 14). Micro Air Vehicles Hold Great Promise, Challenges. Aviation Week and Space Technology, 146, 67-70.

Taussig, R. T. (1984, November). Wave Rotor Turbofan Engines for Aircraft. Mechanical Engineering, 106, 60-66.

Timnat, Y. M. (1996). Advanced Airbreathing Propulsion. (Original ed.). Malabar, FL: Krieger.

Welch, G. E., Jones, S.M., \& Paxson, D. E. (1995). Wave Rotor-Enhanced Gas Turbine Engines. $31^{\text {st }}$ Joint Propulsion Conference and Exhibit Cosponsored by AIAA, ASME, SAE, and ASEE (NASA Technical Memorandum 106998; AIAA-95-2799). San Diego, CA, July 10-12, 1995.

Welch, G. E., Jones, S. M., \& Paxson, D. E. (1997). Wave-Rotor-Enhanced Gas Turbine Engines. Journal of Engineering for Gas Turbines and Power, 119, 469-477.

Wilson, J., \& Paxson, D. (1995). Optimization of Wave Rotors for Use as Gas Turbine Engine Topping Cycles. 1995 Aerospace Atlantic Conference and Exposition Sponsored by the Society of Automotive Engineers (NASA Technical Memorandum 106951). Dayton, OH, May 23-25, 1995. 